\title{
Análise dos processos secretariais das unidades acadêmicas da universidade federal do Pará
}

\author{
Analysis of secretarial processes of academic units of Pará federal university \\ Raul Vitor Oliveira Paes ${ }^{1}$, Ligia Terezinha Lopes Simonian ${ }^{2}$ e Marcelo de Souza Correia ${ }^{3}$ \\ ${ }^{1}$ Universidade Federal do Pará, Brasil, Mestrado em Gestão Pública, e-mail: rauloliverpaes@gmail.com \\ ${ }^{2}$ Universidade Federal do Pará, Brasil, Doutorado em Antropologia, e-mail: simonianl@gmail.com \\ ${ }^{3}$ Universidade Federal do Pará, Brasil, Mestrado em Administração, e-mail: marscorreia@yahoo.com.br
}

Recebido em: 19/08/2018 - Revisado em: 15/02/2019 - Aprovado em: 05/04/2019 - Disponível em: 01/07/2019

\section{Resumo}

Um dos contextos prementes das Instituições Federais de Ensino (IFES) é o processo de adoção de tecnologias de gestão fomentadas pelo Governo Federal, através da força da legislação vigente e em experiências de adoção dessas tecnologias pelas IFES para otimização de processos e para a prestação de melhores serviços com foco no cliente/usuário. Assim, justifica-se a presente pesquisa, com a seguinte problemática adotada: quais são os processos secretariais que podem ser melhorados, pela visão das Secretarias Executivas do Campus Universitário de Belém da Universidade Federal do Pará (UFPA)? Para se chegar à resposta foi definido como objetivo geral: analisar os processos desenvolvidos nas secretarias executivas das Unidades Acadêmicas da UFPA, do campus de Belém. Desdobrando nos seguintes objetivos: identificar os processos desenvolvidos pelos secretários executivos das Unidades Acadêmicas do Campus Universitário de Belém, levantar os processos priorizados pelos secretários executivos, mapear os processos priorizados e propor melhorias para os mesmos. A pesquisa teve teor descritivo, com técnicas de coleta de entrevistas semiestruturadas e questionários, além das técnicas combinadas de análise de conteúdo e triangulação de dados. Os resultados apontam para a identificação de nove processos desenvolvidos pelas Secretarias Executivas, com priorização e mapeamento de dois deles: Assessoria à direção geral e Gestão de documentos, com as respectivas propostas de melhoria, além de notarse que a análise de processos via mapeamento é uma tecnologia aderente que pode ser aplicada em contextos organizacionais universitários.

Palavras-chave: Secretariado. Processos. Universidade.

\section{Abstract}

One of the present contexts in Higher Education Institution (HEI) is adopt process the management technologies for the Federal Government, across the law and the experiences the adoption these technologies for the HEI to optimize processes and for services with 
focus of client/user. Thus, we proposed the following question: what secretarial processes could improve, in the eyes of executive secretaries of University Campus of Belem at Federal University of Para (UFPA)? To get an answer, it was defined as a general objective: analyze the developed processes in executive secretaries of Academic Units of UFPA, in Belem campus. Unfolding in following aims: identifying processes developed by executive secretaries of Academic Units of University Campus of Belem, mapping prioritized processes and proposing improvement for the same. The research has descriptive content, with collect techniques of semi-structured interviews and questionnaires, beyond of combined techniques of content analysis and data triangulation. The results pointed for an identification of nine processes developed of Executive Secretaries, with prioritizing and mapping of two them: General Direction Advisory and Documents' Management, with the respective proposals of improvement, beyond conclude that process 'analysis for mapping is an adherent technology that can apply in universities organizational contexts.

Keywords: Secretariat. Processes. University.

\section{Introdução}

A gestão pública brasileira tem passado por diversas transformações em suas estruturas e processos, perpassando pelas tecnologias com o propósito de auxiliar na otimização da prestação de serviços públicos com mais qualidade e efetividade, dentre eles o Sistema Eletrônico de Informações - SEI! (SOFTWARE PÚBLICO BRASILEIRO, 2015). Dentre as organizações públicas que merecem destaque em relação às transformações, as universidades públicas federais são objetos de alguns estudos (FRANCISCO et al., 2012; GARCIA; FARIAS FILHO; GARCIA HERREROS, 2013). Isso ocorre devido à valorização político-financeira que elas têm recebido nos últimos anos, bem como pelas pressões normativas para adoção de tecnologias de gestão e planejamento.

Nas organizações privadas e públicas, discute-se acerca de tecnologias e ferramentas com o objetivo de prover eficiência em suas atividades e efetividade, quando na entrega de produtos e serviços. Inclusive, uma delas é a gestão por processos, que tem ganhado destaque no serviço público recentemente (GISSONI; COSTA JÚNIOR, 2016; OLIVEIRA; GROHMANN; MARQUETTO, 2016), quando se trata de estudos empíricos nas Instituições Federais de Ensino Superior.

A gestão e o mapeamento por processos têm sido alvo estudos internacionais, como nas áreas de saúde, educação, centros de investigação e em revisões de literatura (GALVISLISTA; GONZÁLEZ-ZABALA, 2014; HERNÁNDEZ-NARIÑO et al., 2016), além de estudos nacionais nestas mesmas áreas no contexto público (ATHAYDES; ARAÚJO, 2016; SALGADO et al., 2013). Isso merece uma atenção especial quanto à temática, no que se refere ao estudo de metodologias e práticas de identificação e análise de processos de trabalho em ambientes diversos. Desse modo, revela-se a aderência de uma gestão voltada a processos nas mais diversas necessidades.

A gestão pública brasileira é marcada por uma série de complexidades, que perpassam por todos os desafios e oportunidades referentes às práticas e problemas de gestão. Assim, a gestão universitária acompanha e possui tais problemáticas, e muito se discute sobre tecnologias e ferramentas que possam acompanhar as demandas para entrega de produtos e serviços aos usuários. Então, essa se transforma na razão principal do presente estudo. 
Além do mais, importa que se perceba o impacto de processos pela visão das secretarias executivas e seus desdobramentos.

Assim, questiona-se: quais os processos de trabalho que podem ser melhorados nas secretarias executivas do Campus Universitário de Belém da Universidade Federal do Pará (UFPA)? Para se chegar à resposta foi definido como objetivo geral: analisar os processos desenvolvidos nas secretarias executivas das Unidades Acadêmicas da Universidade Federal do Pará (UFPA), do campus de Belém. E como objetivos específicos: a) Identificar os processos desenvolvidos pelos secretários executivos das Unidades Acadêmicas do Campus Universitário de Belém; b) Levantar os processos priorizados pelos secretários executivos das Unidades Acadêmicas do Campus Universitário de Belém; c) Mapear os processos priorizados, e d) Propor melhorias para os processos priorizados.

No tocante à estrutura do trabalho, ele está dividido em cinco seções, incluindo esta introdução. Logo após, parte-se para o referencial teórico, com os tópicos de gestão de processos, mapeamento de processos e secretariado, com enfoque às Instituições Federais de Ensino Superior (IFES). Adiante, serão apresentados os procedimentos metodológicos que nortearam o trabalho, com sequência, na análise e discussão dos resultados. Finalmente, prossegue-se com as considerações finais e referências utilizadas no estudo.

\section{Referencial Teórico}

\subsection{Gestão de Processos em Instituições Federais ee Ensino Superior}

As organizações, atualmente, necessitam de ferramentas que documentem e deixem claros os procedimentos e atividades necessárias para que se atinjam os objetivos organizacionais. E, desse modo, a gestão voltada a processos ganhou destaque para aplicação de estudos e práticas organizacionais e, assim, favorece a implementação dela nas organizações (ALVES FILHO, 2011; HERNÁNDEZ-NARIÑO et al., 2016; PRADELLA; FURTADO; KIPPER, 2012). Isso porque que é uma ferramenta com a qual se procura abranger todos os atores organizacionais e seus modos de operação em busca de melhorias.

Ao se falar em gestão por processos é preciso entender que processo é o meio no qual se procura agregar valor a um produto ou serviço, buscando o atendimento dos seus clientes. Como se depreende de McHugh, Pendleblury e Wheeler (1995), processo é a atividade que recebe insumo específico, tendo capacidade de adicionar seu valor organizacional e transformá-lo, criando dessa forma um resultado útil, tanto para o receptor vertical, quanto para o horizontal.

Desse contexto e a partir da abordagem sistêmica que estruturou a gestão de processos, conceitos múltiplos surgiram para explicar cada um dos componentes da gestão (PRADELLA; FURTADO; KIPPER, 2012; RODRIGUES et al., 2016; SORDI, 2014). Assim, palavras como "processos de suporte", "processos de gestão", "fluxos" e "atividades", passaram a integrar o repertório organizacional para a compreensão da existência e propósitos coletivos. A partir da literatura consultada, foi possível sintetizar um vocabulário comum para entendimento dos atores organizacionais, ilustrado pelo Quadro 1, mostrando cada conceito e seu significado relacionado a processos: 
Quadro 1 - Conceitos sobre processos

\begin{tabular}{|l|l|l|}
\hline $\mathbf{N}^{\mathbf{0}}$ & \multicolumn{1}{|c|}{ CONCEITO } & \multicolumn{1}{c|}{ SIGNIFICADO } \\
\hline 1 & $\begin{array}{l}\text { Processo de negócio ou } \\
\text { de cliente }\end{array}$ & $\begin{array}{l}\text { Sequência de trabalhos que atendem um ou mais objetivos organizacionais e } \\
\text { que tem por objetivo agregar valor pelo ponto de vista do cliente final. Eles } \\
\text { caracterizam a atuação da organização. }\end{array}$ \\
\hline 2 & $\begin{array}{l}\text { Processos Primários } \\
\text { Processos de Núcleo }\end{array}$ & $\begin{array}{l}\text { Processos multifuncionais que direcionam as entregas de valor para o } \\
\text { cliente/usuário }\end{array}$ \\
\hline 3 & Processos de Suporte & $\begin{array}{l}\text { Processos estruturados para dar suporte aos processos primários, gerenciando } \\
\text { recursos e infraestrutura necessária para os processos primários. Não entregam } \\
\text { valor diretamente ao cliente/usuário final, porém podem ser críticos e } \\
\text { estratégicos para as organizações, quando interage efetivamente com os } \\
\text { processos primários. }\end{array}$ \\
\hline 4 & Processos de Gestão & $\begin{array}{l}\text { Processos de medição, controle e monitoramento de atividades } \\
\text { organizacionais. Também não conferem valor direto ao cliente/usuário final, } \\
\text { entretanto também são necessários para que a organização opere com } \\
\text { eficiência e eficácia. }\end{array}$ \\
\hline 5 & Atividades & $\begin{array}{l}\text { Unidades lógicas de trabalho executadas dentro de um processo, também } \\
\text { podendo serem relacionados como "conjunto de tarefas". }\end{array}$ \\
\hline 6 & Tarefas & $\begin{array}{l}\text { Partes específicas do trabalho/atividade, ou também, menor enfoque no } \\
\text { processo, podendo ser caracterizado por um elemento ou subconjunto da } \\
\text { atividade. }\end{array}$ \\
\hline 7 & Fluxo de trabalho & $\begin{array}{l}\text { Descrição de sequência de execução das diversas atividades compostas, } \\
\text { indicando uma atividade ou mais atividades. }\end{array}$ \\
\hline
\end{tabular}

Fonte: elaboração própria, com dados de Pradella; Furtado; Kipper (2012), Rodrigues et al. (2016) e Sordi (2014).

Ao levar-se em consideração os termos apresentados pelo Quadro 1, as expressões "Processos de cliente", "Processos deSuporte”, "Atividades”, “Tarefas" e "Fluxo de Trabalho" são as que terão maior valor para a classificação e descrição dos processos organizacionais. Brodbeck, Hoppin e Bobsin (2016) ressaltam que a capacitação prepara conceitualmente e metodologicamente os atores organizacionais para atuação em processos e, portanto, conhecer os termos que norteiam a temática passa a ser fundamental.

Ainda que as universidades estejam passando por discussões e transformações em suas estruturas, pessoas e processos, é de salientar-se que ocorrem de modo lento, em relação às adoções de tecnologias de gestão. Além do mais, há pouco aporte teórico e instrucional para adaptação de programas de gestão e melhoria em processos para as organizações públicas (BIAZZI; MUSCAT; BIAZZI, 2011; MÜCKENBERGER et al., 2013). Note-se, no entanto, que isso dificulta a divulgação de práticas relacionadas a processos no ambiente acadêmico e, consequentemente, a adoção dessas tecnologias nos ambientes educacionais federais.

Outro fator considerado facilitador pelos mesmos autores foi a pressão por meio de obrigações legais. Brodbeck, Hoppen e Bobsin (2016) observaram que normativas do Tribunal de Contas da União (TCU) e da Presidência da República (como o projeto Esplanada Sustentável) constituíram-se como elementos que justificam a importância de usos como a tecnologia de gestão de processos. Também, outros fatores têm que ser considerados para a implantação bem-sucedida de programas dessa natureza, tais como a política da organização, as práticas de gerenciamento, a cultura organizacional, o apoio da alta direção/ administração (ALVARENGA-NETTO, 2004) etc.

\subsection{Mapeamento de Processos com a Notação BPMN}

Dentro da gestão de processos, existe a etapa de mapeamento de processos, no qual o processo é destrinchado em etapas e atividades para descrição. Assim, o mapeamento configura-se como um processo que demanda tempo e precisão para conhecer todas as 
etapas com o intuito de apontar quais os pontos que precisam ser melhorados (SANTOS, 2017). Ou seja, o mapeamento se concentra na atenção ao processo propriamente dito.

E, para melhor visualização dos processos mapeados, é necessário o uso de ferramentas que auxiliem na compreensão (ALVES FILHO, 2011; ATHAYDES; ARAÚJO, 2016). Existem diversas metodologias para proceder ao mapeamento de processos, como, por exemplo: Modelo de Análise e Melhoria de Processos (MAMP), Metodologia GEPRO (Gestão de Processos), o Modelo VW (Modelo dos Sete Passos) e o DOMP (Documentação, Organização e Melhoria de Processos) (PRADELLA; FURTADO; KIPPER, 2012). Todas elas apresentam diferenças quanto aos passos e sua execução, porém são similares no que se refere à finalidade de mapeamento e documentação de processos.

As traduções práticas do mapeamento de processos são efetuadas pelos mapas de processos, os quais são produtos que apontam, com representações gráficas modeladas, relações entre pessoal, atividades, informações e objetos envolvidos (GISSONI; COSTA JÚNIOR, 2016). Ou seja, esses produtos informam graficamente como ocorrem os processos de fato e são matrizes para oportunidades de melhorias.

De maneira gráfica, apresenta-se a notação BPMN como uma linguagem estruturada que permite o desenho dos processos com padronização e compreensão clara das relações setoriais e organizacionais. BPMN é a sigla para Business Process Modeling Notation, ou numa tradução livre, Notação para Modelagem de Processos de Negócio. Tal notação foi criada por uma organização não-governamental especializada em processos, a Business Process Management Initiative (BPMI) (GISSONI; COSTA JÚNIOR, 2016), sendo difundida a partir de 2004.

A notação BPMN é composta por algumas descrições, dentre elas os conceitos de atividades, que são os descritores aparentes que enumeram as etapas dentro do processo. Porém, provavelmente, em determinados mapeamentos, há ocorrências de muitas atividades para apenas um processo, o que pode torná-lo longo e demasiadamente cansativo para leitura. Assim, de acordo com Brasil (2013), temos o conceito de subprocesso, no qual é uma composição de uma atividade com várias tarefas internas.

Também temos os eventos, que são representações de ocorrências dentro de um processo (Brasil, 2013), sendo caracterizados de acordo com o BPMN em: eventos de início, eventos intermediários e eventos de fim.

Segundo Brasil (2013), Gissoni, Costa Júnior (2016) e Sganderla (2012), os eventos de início são os norteadores de partida do processo de trabalho e tem como representação círculo de linha simples. Já os eventos intermediários ressaltam ocorrência de eventos durante o processo, são representados pelos círculos de linha dupla e não começam e nem terminam o processo. E os eventos de fim indicam a finalização do processo, sem fluxos de continuidade e são representados pelos círculos de linha grossa.

Após a compreensão crítica dos processos e identificação completa dos mesmos através da análise, procede-se a etapa de melhoria. Também é identificada como redesenho, pela necessidade de proposição de novas formas dos processos identificados como críticos, ou seja, aqueles que demandem mais alinhamento (PRADELLA; FURTADO; KIPPER, 2012). No redesenho, o processo é reestruturado com base nos resultados obtidos da análise.

Com a notação BPMN, as mesmas representações virtuais podem desenhar as adequações, facilitando a uniformização no mapeamento e na melhoria e, consequentemente, no entendimento do processo pelas partes interessadas. Com as devidas alterações, as 
proposições dão origem a um novo processo, preparando-o para ser documentado e compartilhado aos interessados, com novos fluxos e etapas. O que resulta na mudança da dinâmica organizacional.

\subsection{Secretariado Executivo e Atuação nas IFES}

O desenvolvimento da profissão, no Brasil, remonta-se à década de 1940, com o surgimento dos cursos técnicos e com a posterior evolução para os cursos de secretariado executivo, em nível superior, com estruturação mercadológica e curricular relativamente recente (LEAL; DALMAU, 2014). Atualmente, no cenário brasileiro coexistem tanto os cursos técnicos, como os níveis superiores de bacharelado e tecnologia na área, além de cursos de especialização.

A regulamentação sobre o secretariado foi sancionada em 1978, quando foi instituída a atividade de secretário, por meio da Lei № 6.556/1978 (NONATO JÚNIOR, 2009). Em 1985, promulgou-se a Lei № 7.377/1985, que dispõe sobre a profissão de secretário e divide a profissão em duas formas: secretário executivo (nível superior) e técnico em secretariado (nível técnico) (BRASIL, 1996, 1985, 1978), o que reflete na necessidade e no reconhecimento da atuação profissional nas organizações privadas e públicas.

Para os objetivos desse artigo e de acordo com Paes et al. (2015), a assessoria pode ser entendida como uma assistência executiva e adjunta aos órgãos decisórios, em que funciona como orientadora e aconselhadora de planos e procedimentos, multiplicadora de processos e prestadora de serviços especializados, seja no âmbito técnico, como no âmbito executivo. A partir dessa análise e a partir de Castelo (2007) e de Paes et al. (2015), a assessoria praticada pelo secretário executivo, ou a assessoria secretarial é composta pelas variáveis:

a) habilidade de comunicação e no gerenciamento de informações, caracterizando, desse modo, a ênfase da gestão da comunicação e da informação;

b) compreensão e aplicação da gestão de conflitos internos e externos;

c) conhecimento da organização como um todo, caracterizando assim uma visão organizacional holística;

d) planejamento e aplicação da liderança em equipes de trabalho, lidando com a gestão de equipes;

e) domínio e aplicação dos fundamentos da gestão organizacional, caracterizando-se como gestor em seu setor e servindo de suporte gerencial aos demais setores, exercendo, mutuamente, as áreas de gestão secretarial e técnicas de assessoramento;

f) aplicação da ética e sensatez em seus pronunciamentos e ações, constituindo-se então na ética profissional;

g) conhecimento/visão da cultura organizacional, seus nichos mercadológicos (ou de atuação, dependendo do perfil da organização) e perfis de clientes ou usuários.

Assim, percebe-se que a atuação secretarial pode estar tanto no âmbito privado quanto público. Exemplo disso é a instituição do Plano de Cargos e Carreira dos TécnicoAdministrativos em Educação (PCCTAE), através da Lei № 11.091/2005, a profissão de secretário executivo constou na descrição e classificação dos cargos (LEAL; FIATES, 2013). A descrição dos cargos encontra-se anexa ao Ofício № 15/2005/CGGP/SAA/SE/MEC, expedido pelo Ministério da Educação (Quadro 2), em que consta o cargo de secretário executivo, no qual são transpostas as seguintes atribuições: 
Quadro 2 - Atividades secretariais executivas definidas de acordo o MEC

\begin{tabular}{|c|c|c|}
\hline $\mathbf{N}^{\mathbf{0}}$ & ATIVIDADE & DETALHAMENTO/CONJUNTO DE TAREFAS \\
\hline 1 & Assessorar direções & $\begin{array}{l}\text { Administrar agenda pessoal das direções; despachar com a direção; } \\
\text { colher assinatura; priorizar, marcar e cancelar compromissos; definir } \\
\text { ligações telefônicas; administrar pendências; definir encaminhamento de } \\
\text { documentos; assistir à direção em reuniões; secretariar reuniões. }\end{array}$ \\
\hline 2 & Atender pessoas & $\begin{array}{l}\text { Recepcionar pessoas; fornecer informações; atender pedidos, solicitações } \\
\text { e chamadas telefônicas; filtrar ligaços; anotar e transmitir recados; } \\
\text { orientar e encaminhar pessoas; prestar atendimento especial a } \\
\text { autoridades e usuários diferenciados. }\end{array}$ \\
\hline 3 & Gerenciar informações & $\begin{array}{l}\text { Ler documentos; levantar informações; consultar outros departamentos; } \\
\text { criar e manter atualizado banco de dados; cobrar ações, respostas, } \\
\text { relatórios; controlar cronogramas, prazos; direcionar informações; } \\
\text { acompanhar processos; reproduzir documentos; confeccionar clippings. }\end{array}$ \\
\hline 4 & Elaborar documentos & $\begin{array}{l}\text { Redigir textos, inclusive em idioma estrangeiro; pesquisar bibliografia; } \\
\text { elaborar relatórios; digitar e formatar documentos; elaborar convites e } \\
\text { convocações, planilhas e gráficos; preparar apresentações; transcrever } \\
\text { textos; taquigrafar ditados, discursos, conferências, palestras, inclusive } \\
\text { em idioma estrangeiro; traduzir em idioma estrangeiro, para atender às } \\
\text { necessidades de comunicação da instituição. }\end{array}$ \\
\hline 5 & Controlar correspondência & $\begin{array}{l}\text { Receber, controlar, triar, destinar, registrar e protocolar correspondência } \\
\text { e correspondência eletrônica (e-mail); controlar malote. }\end{array}$ \\
\hline 6 & Organizar eventos e viagens & $\begin{array}{l}\text { Estruturar o evento; fazer checklist; pesquisar local; reservar e preparar } \\
\text { sala; enviar convite e convocação; confirmar presença; providenciar } \\
\text { material, equipamentos e serviços de apoio; dar suporte durante o } \\
\text { evento; providenciar diárias, hospedagem, passagens e documentação } \\
\text { legal das direções (passaportes, vistos). }\end{array}$ \\
\hline 7 & $\begin{array}{l}\text { Supervisionar equipes de } \\
\text { trabalho }\end{array}$ & $\begin{array}{l}\text { Planejar, organizar e dirigir serviços de secretaria; estabelecer } \\
\text { atribuições da equipe; programar e monitorar as atividades da equipe. }\end{array}$ \\
\hline 8 & Arquivar documentos & $\begin{array}{l}\text { Identificar o assunto e a natureza do documento; determinar a forma de } \\
\text { arquivo; classificar, ordenar, cadastrar e catalogar documentos; arquivar } \\
\text { correspondência; administrar e atualizar arquivos. }\end{array}$ \\
\hline 9 & Outros & $\begin{array}{l}\text { Utilizar recursos de informática em seu trabalho e executar outras tarefas } \\
\text { da mesma natureza e nível de complexidade, associadas ao ambiente } \\
\text { organizacional inserido. }\end{array}$ \\
\hline
\end{tabular}

Fonte: adaptado de Brasil (2005), Leal e Fiates (2013).

De acordo com a classificação do cargo de secretário executivo, compete ao mesmo, finalmente, assessorar nas atividades de ensino, pesquisa e extensão, dada a natureza institucional o qual está inserido (BRASIL, 2005; LEAL; DALMAU, 2014), em continuação na descrição. Por outro lado, nota-se que, tanto as atividades como o detalhamento das mesmas, guardam diversas relações com as áreas de conhecimento profissional propostas pela assessoria secretarial, com as devidas adaptações para a gestão pública. Assim, tanto as propostas teóricas, quanto as descrições executórias e práticas contribuem para a evolução prática do profissional em termos de assessoria e gestão internas e organizacionais.

\section{Procedimentos Metodológicos}

Para os efeitos deste trabalho, como a pesquisa ocorreu em um contexto específico, a natureza é aplicada. Para Roesch (1999), a pesquisa aplicada tem o intento de produção de soluções potenciais para aplicação em problemas humanos. E no que se refere à abordagem, a pesquisa será qualitativa, tendo em vista que os ambientes naturais das Unidades Acadêmicas serão a fonte direta para a coleta de dados, interpretação de fenômenos e significações (ALYRIO, 2009). Outra classificação é um estudo de caso (YIN, 2015), para melhor compreensão da realidade organizacional.

No tocante aos objetivos, a pesquisa é descritiva, pois descreve as características de determinada população e fenômeno (GERHARDT, SILVEIRA, 2009), sendo a população composta por servidores investidos na função de secretário executivo e interação com o mapeamento de processos. 
A pesquisa também contou com os procedimentos de levantamento bibliográfico e documental, a partir da aplicação de métodos bibliométricos (GUEDES, 2012) em fase exploratória. Foram consultados três livros que tratam sobre a gestão de processos (ALVES FILHO, 2011; PRADELLA; FURTADO; KIPPER, 2012; SORDI, 2014), em que o critério principal residiu nas atualizações recentes sobre a temática.

Também houve consultas na Biblioteca Digital Brasileira de Teses e Dissertações, mantida pelo Instituto Brasileiro de Informação em Ciência e Tecnologia (BDTD/IBICT http://bdtd.ibict.br/vufind/), em que foram retornados 72 documentos científicos, entre teses e dissertações, entre os períodos de 2008 a 2017, usando os descritores: "mapeamento de processos" and "universidades federais". Com os descritores "mapeamento de processos" e "instituição federal de ensino" houve o retorno de 35 trabalhos.

Ainda sobre a busca descrita acima, após uma análise mais específica, apenas 6 documentos (dissertações) versavam especificamente sobre mapeamento de processos e universidades federais. Sobre mapeamento de processos e instituição federal de ensino, apenas 7 trabalhos são relacionados entre ambas as temáticas, para uma verificação abrangente.

Do mesmo modo, também foram consultados documentos científicos no portal de periódicos da Coordenação de Aperfeiçoamento de Pessoal de Nível Superior (CAPES http://www.periodicos.capes.gov.br/), para verificação de artigos publicados sobre as temáticas, aplicando-se os descritores "mapeamento de processos" and "instituições federais de ensino", no que houve retorno de um artigo publicado em 2013. Assim, nota-se a incipiente publicação envolvendo ambas as temáticas em periódicos. As demais referências internacionais também foram coletadas através de revisões das referências publicadas nos artigos nacionais.

Quanto aos procedimentos de coleta de dados, houve divisão em etapas. A primeira se concentrou na adoção de grupos focais (FREITAS, 2016) para levantamento de processos com os secretários executivos de função. Adotou-se a técnica de seleção intencional (THIRYCHERQUES, 2009), para a seleção dos secretários que estão lotados em Institutos e Núcleos, por entender que representam as características da população pretendida, como ser responsável pelo Setor da Secretaria Executiva e ocupar a função de secretário executivo no setor. Foram realizadas duas entrevistas entre os meses de abril e maio de 2017, em um Instituto na UFPA, no que foram identificados nove processos secretariais.

Esclarece-se que, em relação à segunda etapa, questionários foram aplicados para priorização de processos aos 16 SE de Institutos e Núcleos, os quais tivemos os seguintes processos prioritários: Assessoria à direção geral e Gestão de documentos. Ressalta-se que essa seleção foi possível chegar consultando documentos oficiais da UFPA sobre Institutos e Núcleos. Posteriormente, foram realizadas entrevistas individuais à nove sujeitos da pesquisa para descrição das etapas de cada processo, visando a modelagem e melhoria destes.

A definição da quantidade de entrevistados atendeu ao critério de ponto de saturação na pesquisa qualitativa (THIRY-CHERQUES, 2009). Nestes termos, se recomenda um mínimo de oito observações a serem contempladas pela pesquisa e no máximo de 15, já com as quantidades de confirmação previstas nas observações. Nesse sentido, foi possível a confirmação de resultados com nove entrevistas no estudo. 
As técnicas de análise de dados foram a análise de conteúdo e a triangulação. Sobre a análise de conteúdo, Bardin (2011) aponta que há três fases: pré-analise, em que se estabelece um contato inicial com as entrevistas em grupo e individuais; exploração do material, em que foram definidas as seguintes categorias de análise: Processos Secretariais; Processos Priorizados; Processos Mapeados e Melhoria de Processos. Por fim, a fase de tratamento do material, inferência e interpretação, em que foram obtidas análises e inferências a partir dos processos levantados, priorizados, modelados e melhorados de acordo com o desenho de mapas de processos e diagramas, nos termos da notação BPMN.

Sobre a triangulação, Yin (2015) entende que é uma técnica que lida com uma variedade de documentos para análises e comparações, como entrevistas, observações, planilhas, entre outros, para gerar representações de processos para a presente pesquisa. As fontes de dados usadas foram as entrevistas em grupos, entrevistas individuais e análises documentais das regulamentações legais da UFPA.

No tocante ao mapeamento de processos, a abordagem usada foi de baixo para cima (bottom-up), sendo aplicada para melhoria de processos de um departamento ou para gerar documentação inexistente (MÜCKENBERGER et al., 2013). Após o tratamento por meio da descrição, as atividades foram agrupadas e transformadas em mapas de processos com o software freeware Bizagi Process Modeler ${ }^{\circledR}$.

\section{Caracterização do Ambiente de Estudo: Resultados e Discussões}

AUFPA - autarquia especial vinculada ao Ministério da Educação-éa maior instituição de ensino na Amazônia; foi criada pela Lei no 3.191, de 2 julho de 1957, pelo então Presidente Juscelino Kubitschek de Oliveira. Atualmente, a Universidade é constituída por 12 campi, sendo um na capital e onze no interior, e conta com Unidades Acadêmicas distribuídas em 14 Institutos, sete Núcleos, dois Hospitais Universitários, uma Escola de Aplicação e duas Escolas Técnicas de Música e Teatro e Dança (TEIXEIRA, 2014; UNIVERSIDADE FEDERAL DO PARÁ, 2017), sendo que a maioria das Unidades ficam localizadas em Belém.

Em relação ao pessoal docente e técnico-administrativo, a UFPA possui 2.359 docentes efetivos do Magistério Superior, 246 docentes efetivos no Magistério do Ensino Básico, Técnico e Tecnológico (Carreira EBTT), 236 docentes substitutos e visitantes, além de 2.541 técnico-administrativos em educação dos cargos os mais diversos (UNIVERSIDADE FEDERAL DO PARÁ, 2017), ressaltando um quadro de pessoal expressivo e que atende a diversos níveis de ensino e às demandas administrativas internas, podendo ser aprimorado.

\subsection{Processos Secretariais}

A primeira etapa consistiu em dois grupos focais, ocorridos nos meses de abril e maio. No primeiro grupo focal, ocorrido no final de abril em um Instituto no Campus Universitário de Belém, contou com a presença de cinco secretários, sendo quatro secretários executivos ligados aos Institutos e uma secretária acadêmica, ligada à uma Pós-Graduação. Cada secretário orientado a descrever até três atividades que consideravam relevantes na atuação profissional. Na Figura 1, revelam-se as atividades destacadas pelos secretários: 
Figura 1 - Descrição de atividades pelos secretários participantes

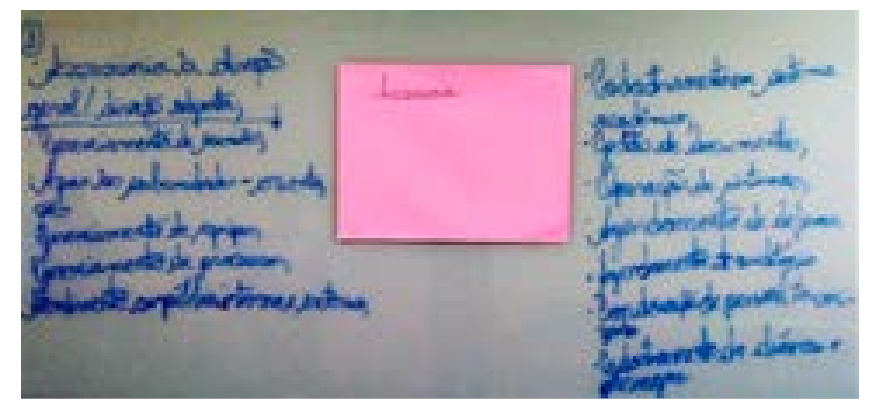

Fonte: acervo da pesquisa.

Essa entrevista em grupo teve duração de 1h30min. Como o primeiro grupo focal foi encerrado na descrição das atividades, devido à disponibilidade limitada dos participantes, então necessitou-se organizar um segundo grupo focal. A atividade ocorreu na segunda quinzena do mês de maio, com a participação de quatro secretários executivos de Institutos. Esse grupo teve o objetivo de agrupar os processos de acordo com a descrição das atividades, previamente informado aos participantes.

A segunda entrevista em grupo teve duração de 45 minutos. Como resultados, foram identificados nove processos secretariais e validados pelos mesmos secretários no momento da entrevista. No Quadro, 3 identificam-se os nomes dos processos:

Quadro 3 - Processos identificados nas secretarias executivas dos Institutos

\begin{tabular}{|rl|rl|}
\hline 1) & Assessoria à direção geral; & 6) & Coordenação da agenda; \\
\hline 2) & Gerenciamento de reuniões; & 7) Gestão de documentos; \\
\hline 3) & Gerenciamento da informação; & 8) Operação de Sistemas de Gestão; \\
\hline 4) & Coordenação de equipes; & 9) & Organização de eventos; \\
\hline 5) & Atendimento ao público; & \multicolumn{2}{|c|}{} \\
\cline { 1 - 2 } & &
\end{tabular}

Fonte: dados da pesquisa.

A partir da definição dos processos, é possível inferir que os mesmos estão de acordo com as atribuições descritas dos secretários executivos de acordo com a legislação e a literatura pertinente (LEAL; DALMAU, 2014; BRASIL, 2005). Assim, indica-se a aderência dos processos secretariais como pertinentes e comuns, ao menos indicado pelos secretários executivos dos Institutos.

Com a facilitação da apropriação do conceito de processo percebida quando do desenvolvimento dos grupos focais, então foi mais fluida a definição dos processos pelos mesmos. Rodrigues et al (2016), em um estudo sobre a atuação do profissional de secretariado na gestão de processos, observaram que o profissional apresenta atribuições e competências que permitem atuar na gestão de processos. Logo, o secretário executivo pode dominar tal modelo de gestão com maior facilidade e aplicá-lo em diversos contextos organizacionais.

\subsection{Processos Priorizados}

Posteriormente, na segunda etapa, foi realizada a aplicação de questionários e entrevistas individuais com os secretários executivos. Num primeiro momento, foram enviados e-mails aos secretários apresentando os processos identificados na primeira etapa e solicitando a descrição dos processos identificados no mês de julho de 2017. Após alguns retornos de como melhorar a aplicação das instruções, bem como o retorno baixo 
dos respondentes, foi enviado um questionário online aos responsáveis pelas secretarias executivas via WhatsApp ${ }^{\circledR}$ e e-mail solicitando quais os processos os secretários teriam interesse em mapear, podendo escolher quantos quisessem, sendo o mínimo de três, ocorrendo assim a priorização de processos de trabalho pelos secretários.

O questionário foi aplicado entre julho e agosto de 2017. Os processos que obtiveram maior frequência entre os secretários foram os seguintes: Assessoria à direção geral (100\% das respostas) e Gestão de documentos (58,3\% das respostas). Para identificação dos processos no decorrer do texto, os mesmos serão nominados em P1 (Assessoria à direção geral) e P2 (Gestão de documentos).

A partir das respostas obtidas, foram realizadas entrevistas estruturadas individuais com os responsáveis das secretarias com o intuito de obter as descrições das atividades realizadas. Nessas entrevistas, os secretários foram orientados a descrever cada um dos processos com base nas atividades realizadas, sem necessitar de representação gráfica. Foi mostrado um exemplo de processo descrito nos questionários, de modo a explicitar como ocorre a descrição das etapas. O período das entrevistas foi realizado no mês de agosto de 2017, de acordo com a disponibilidade do profissional em seu setor.

Após a realização das entrevistas, todas as descrições das etapas e atividades foram transcritas em planilhas do software Microsoft Excel $\AA$, para a replicação adequada nos desenhos dos processos. Desse modo, ocorreu a etapa de identificação das principais diferençase semelhanças entre os três processos priorizados, analisando-se comparativamente entre três Institutos e/ou Núcleos. Como se depreende de Sganderla (2012), o mapeamento ocorreu com base no modelo AS IS, que é o método de levantar o retrato do processo.

\subsection{Processos Mapeados}

Após as entrevistas e as descrições dos processos, os prioritários tiveram o tratamento das etapas através da construção de mapas por meio do programa Bizagi Process Modeler®.

Sobre o Processo Assessoria à direção geral (P1), descrito como o mais comum entre os responsáveis das secretarias executivas, de maneira geral, consiste em atividades de recepção de demandas internas ou externas, análise da demanda para verificação, coleta de dados e informações para subsidiar a tomada de decisão e apresentação à tomada de decisão ao órgão superior imediato, no caso, a direção geral, por se tratar de unidades acadêmicas.

Tais considerações foram análises descritivas breves para compreensão dos mapas dos processos realizados. Sobre o P1, embora haja um entendimento semelhante quando do seu significado, há diferenças sensíveis em sua execução, ao realizar uma análise comparativa a partir do mapeamento do processo por três unidades.

Em determinado Instituto, por exemplo, há um relacionamento descrito entre Secretaria e Direção, tendo em vista a finalidade do processo, além de uma descrição pormenorizada das etapas e responsabilidades de ambos os setores. Na Figura 2, tem-se o mapa de processo P1 que ocorre na Secretaria Executiva em um Instituto da UFPA: 
Figura 2 - Processo Assessoria à direção geral ocorrente em um Instituto

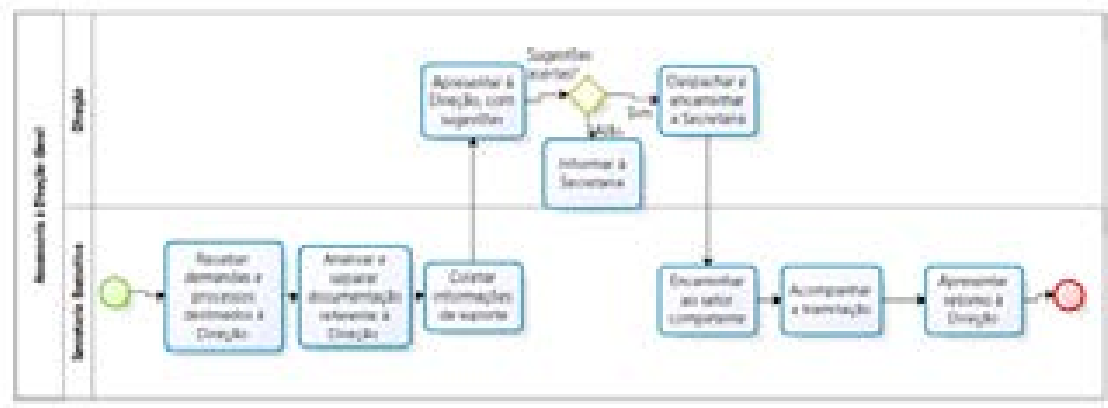

Fonte: dados da pesquisa.

Osegundo processo foi interpretado, pela ordem de prioridade, Gestão de Documentos (P2), de diferentes maneiras pelos secretários. Justifica-se devido à compreensão ampla de atividades que envolvem etapas de Protocolo, Documentação e Arquivo em um mesmo processo.

Ele inclui as atividades de recepção da demanda, consulta de modelos, elaboração de documentos, apresentação à direção, correção de ajustes, assinatura, despacho, encaminhamento, confirmação de recebimento e arquivo de vias recebidas, indicando claramente as responsabilidades da Secretaria e da Direção no processo. Na Figura 3, ilustrase o Processo P2 da Secretaria Executiva de um Instituto:

Figura 3 - Processo Gestão de documentos ocorrente em um Instituto

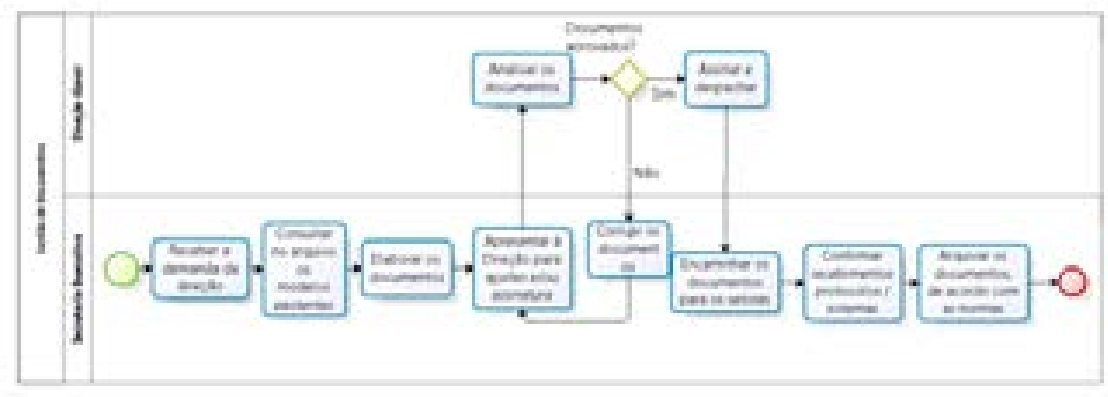

Fonte: dados da pesquisa.

De acordo com os processos definidos pela padronização, percebeu-se a existência de etapas que podem ser aprimoradas para o prosseguimento adequado das atividades; e isso a partir das comparações entre os mapas de processos apresentados, tais como a pertinência da assinatura dos documentos (se exclusivamente pela Direção ou pode ser delegada pela Secretaria) e sobre a existência de modelos de documentos para suporte na elaboração.

\subsection{Melhoria de Processos}

Após os desenhos dos processos como ocorrem, foram propostas melhorias nos mesmos processos com base em análises comparativas de mapas de processos dos Institutos. Sobre o Processo Assessoria à direção geral (P1), dentre os mapas que foram apresentados, 
foi identificado que o mapa apresentado por um determinado Instituto foi o que obteve mais especificações sobre o relacionamento com a Direção Geral, bem como também refletiu respostas de outros respondentes. Logo, na proposta do processo priorizado houve apenas algumas modificações em relação às etapas, bem como na melhor descrição de outras. $\mathrm{Na}$ Figura 4, ilustra-se o mapa de processo proposto para o P1:

Figura 4 - Mapa de Processo Proposto de Assessoria à direção geral

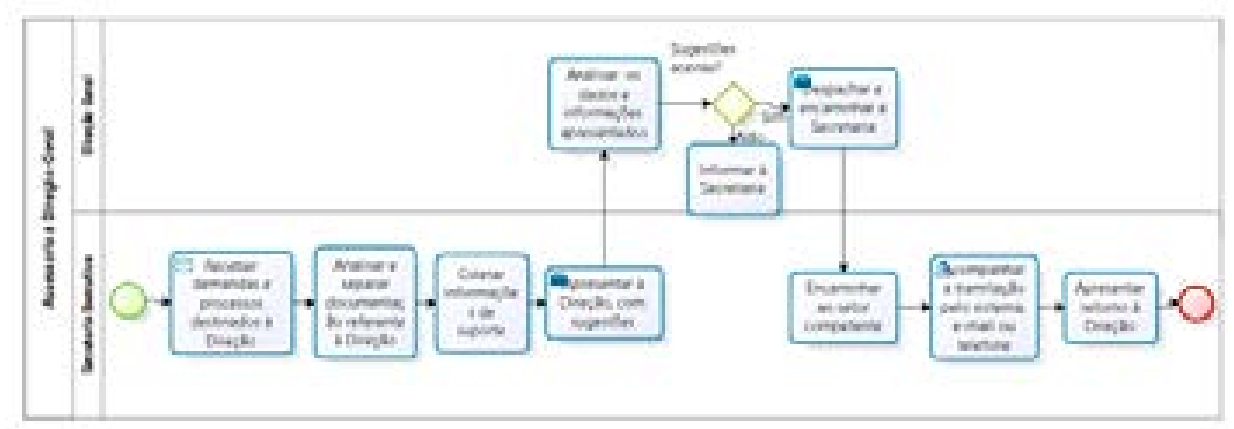

Fonte: dados da pesquisa.

Em relação ao Processo P2 (Gestão de Documentos), foram verificados vários pontos de melhoria para otimização, levando em consideração algumas particularidades encontradas durante os mapeamentos. Assim, também foi proposto um mapa de processo que contemple tal realidade vislumbrada em algumas Secretarias. Na Figura 5, ilustra-se o segundo mapa de processo proposto de Elaboração de Documentos:

Figura 5 - Mapa de Processo Proposto de Elaboração de documentos

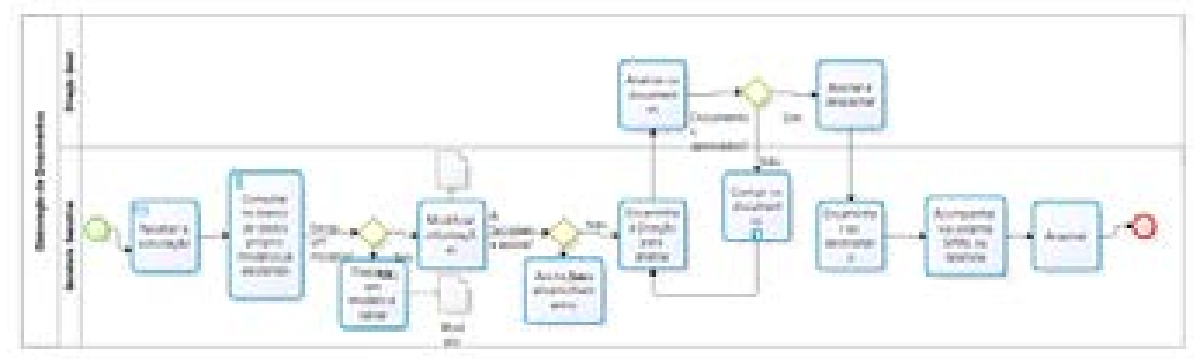

Fonte: dados da pesquisa.

Nesse mapa, devido à inexistência do setor de Protocolo, então não foi considerado o mesmo nessa proposta, apenas sendo a diferença principal. As demais atividades foram absorvidas pela Secretaria, sendo as mesmas inalteradas se comparadas com o processo anterior. Também foi mantido o loop sobre as correções admitindo-se a possibilidade de melhorias quando da apresentação dos documentos à Direção, bem como os gateways decisórios (pontos decisórios representados por losangos) da Secretaria foram mantidos por ser aplicável à mesma realidade.

Também, no mesmo processo, o nome passou a ser "Elaboração de documentos" dados os mesmos retornos observados na apresentação do mapa de processo anterior. Além do mais, é necessário pontuar que pode haver mais de uma proposta de mapeamento de 
um mesmo processo, dada a realidade de diversos entes organizacionais. É importante mencionar que, para as propostas de processos, o método usado foi o TO BE (SGANDERLA, 2012), adequado para as fases de redesenho e melhoria.

\subsection{Outras Análises: Processos e Secretariado}

Com os resultados, pôde-se conferir a relação entre os processos secretariais e sua identificação, bem como na priorização dos processos identificados pelos mesmos. Sobre os dois processos pontuados, Assessoria à direção geral e Gestão de documentos, infere-se que os mesmos guardam relações com o proposto com a assessoria secretarial, uma vez que eles lidam com as áreas de conhecimento de gestão da informação e comunicação e técnicas de assessoramento, principalmente, lidando com os eixos de assessoria e gestão (BRASIL, 2005; CASTELO, 2007; LEAL; FIATES, 2013; PAES et al., 2015). Assim, caracterizam-se como os primeiros processos secretariais priorizados.

Do mesmo modo, os processos também refletem as atividades secretariais requeridas pelo MEC (BRASIL, 2005; LEAL; FIATES, 2013) para a área secretarial. Eles são desdobrados pela descrição de etapas e atividades possibilitada pelo mapeamento de processos.

Outra consideração importante é que a abordagem bottom-up é uma alternativa para mapeamento de processos em organizações públicas, tendo em vista a complexidade das organizações públicas em suas rotinas e processos (MÜCKENBERGER et al., 2013). Como percebido, houve comportamentos de acessibilidade, aceitação e disponibilidade dos sujeitos da pesquisa para participação. Em comparações com a teoria, é possível inferir que os processos secretariais sejam considerados processos de suporte (RODRIGUES et al., 2016; SORDI, 2014), tendo em vista que há processos que servem de apoio para demais ações organizacionais, como o de Assessoria à direção geral e a Gestão/Elaboração de Documentos.

É de se ressaltar, também, que a notação BPMN e a aplicação do software Bizagi são, em razão da característica de aderência do mapeamento, ferramentas úteis e que podem ser aplicadas para ações de estudo e desenho de processos nas instituições e setores públicos (GISSONI; COSTA JÚNIOR, 2016). Ademais, percebeu-se que a instrução dos entrevistados na temática de processos é necessária para compreensão da descrição das etapas (BRODBECK; HOPPEN; BOBSIN, 2016) e de seus desdobramentos.

\section{Considerações Finais}

Com a gestão e as organizações em permanente mudança, tecnologias diversas surgiram para corresponder às demandas organizacionais. A partir dessa premissa, teve-se como objetivo neste artigo analisar os processos desenvolvidos nos setores de Secretarias Executivas das Unidades Acadêmicas do Campus Universitário de Belém da UFPA.

De modo sintetizado, os resultados apontam para a confirmação da compreensão da dinâmica organizacional via mapeamento de processos, bem como para a possibilidade de proposição de melhorias dos processos priorizados; e isso a considerar-se um público específico dos secretários executivos, com claras definições de responsabilidades entre os setores. Por outro lado, os mesmos resultados apontam para diferenças entre os 
mapeamentos que devem ser consideradas como particulares entre as Unidades, bem como para possibilidades de existência de mais de uma proposta de melhoria do mesmo processo.

Outros resultados também foram desdobrados pelo presente estudo, com a classificação dos processos secretariais em processos de suporte, a aderência de abordagens alternativas para mapeamento e modelagem de processos considerando o ambiente organizacional, a possibilidade de aplicação de técnicas e softwares para a construção dos mapas de processos, mesmo em ambientes bastante burocráticos e hierarquizados, entre outros. Nestes termos, o estudo contribuiu para a compreensão prática do secretariado no ambiente organizacional de estudo, a partir da perspectiva do mapeamento de processos, bem entende-se que é possível aprofundar uma das possibilidades de melhorias da gestão pública através da análise e melhoria de processos.

Importa salientar que, em razão da necessidade de priorização e de tempo definido para a realização deste estudo, os demais processos secretariais não foram mapeados. Assim, devido à multiplicidade de resultados de mapeamento e melhorias de processos oriundos deste trabalho, sugerem-se os seguintes temas para estudos futuros, de aplicação tecnológica ou em trabalhos acadêmicos: a) Estudos de mapeamento de processos com foco em uma Unidade, com mais atores envolvidos; b) Estudos de mapeamento e melhoria de processos nos demais processos secretariais identificados pela presente pesquisa.

\section{Referências}

ALVARENGA-NETTO, C. A. Proposta de modelo de mapeamento e gestão por macroprocessos. 2004. 343 p. Tese (Doutorado em Engenharia de Produção) - Universidade de São Paulo, São Paulo, SP, 2004.

ALVES FILHO, B. de F. Processos organizacionais: simplificação e organização. São Paulo: Altas, 2011.

ALYRIO, R. D. Métodos e técnicas de pesquisa em administração. Rio de Janeiro: Fundação CECIERJ, 2009.

ATHAYDES, P. B. C.; ARAÚJO, F. O. Mapeamento e análise do processo de lançamento de notas/ conceitos das Secretarias Acadêmicas do Colégio Pedro II: reflexões e propostas de melhoria. Revista Produção e Desenvolvimento, Rio de Janeiro, v.2, n.3, p.21-36, set./dez., 2016. ISSN: 2446-9580. Disponível em: https://goo.gl/Bw8PYF. Acesso em: 16 mar. 2017.

BARDIN, L. Análise de conteúdo. São Paulo: Edições 70, 2011.

BIAZZI, M.R. de; MUSCAT, A.R.N.; BIAZZI, J.L. de. Modelo de aperfeiçoamento de processos em instituições públicas de ensino superior. Gestão \& Produção, São Carlos, v. 18, n. 4, p. 869-880, 2011. Disponível em: https://goo.gl/mMdTnC. Acesso em: 5 nov. 2017.

BRASIL. Lei n. ${ }^{\circ}$ 6.556, de 5 de setembro de 1978 . Dispõe sobre a atividade de Secretário e dá outras providências. Diário Oficial da União, Brasília - Seção 1 - 5/9/1978, Página 14321 (1978). Disponível em: https://goo.gl/aScXDB. Acesso em: 28 fev. 2017. 
BRASIL. Lei n. ${ }^{\circ}$ 7.377, de 30 de setembro de 1985. Dispõe sobre o exercício da profissão de Secretário, e dá outras providências. Diário Oficial da União, Brasília - Seção 1 - 1/10/1985, Página 14314 (1985). Disponível em: https://goo.gl/ppUjqz. Acesso em: 28 fev. 2017.

BRASIL. Lei n. ${ }^{\circ}$ 9.261, de 10 de janeiro de 1996. Altera a redação dos incisos I e II do art. $2^{\mathbf{0}}$, o caput do art. $3^{\circ}$, o inciso VI do art. $4^{\circ}$ e o parágrafo único do art. $6^{\circ}$ da Lei n. 7.377 , de 30 de setembro de 1985. Diário Oficial da União, Brasília - Seção 1 - 11/1/1996, Página 393 (1986). Disponível em: https://goo.gl/bf9dqD. Acesso em: 28 fev. 2017.

BRASIL. Ofício n. 15/2005/CGGP/SAA/SE/MEC, de 28 de novembro de 2005.

BRASIL. Tribunal de Contas da União. Curso de mapeamento de processos de trabalho com BPMN e Bizagi: Aula 1 - metodologia de mapeamento de processos de trabalho. Brasília, DF: TCU, 2013.

BRODBECK, A. G.; HOPPEN, N.; BOBSIN, D. Uma metodologia para implementação da Gestão por Processos em Organizações Públicas. Revista de Administração da UFSM. Santa Maria, v. 9, n. 4, p. 699-720, set. - dez. 2016. Disponível em: https://goo.gl/CT2Drx. Acesso em: 5 nov. 2017. doi: https://10.5902/19834659 15250 .

CASTELO, M. J. A formação acadêmica e a atuação profissional do secretário executivo. Trabalho de Conclusão de Curso (Graduação em Secretariado Executivo). 129 f. Universidade Estadual de Londrina, Londrina, PR, 2007. Disponível em: https://goo.gl/LpjbGd. Acesso em: 28 fev. 2017.

FRANCISCO, T. H. A.; NAKAYAMA, M. K.; RAMOS, A. M; OLIVEIRA, P. C. A contribuição do PDI nas atividades de planejamento e gestão das instituições de educação superior. Revista Gestão Universitária na América Latina, Florianópolis, p. 81-107, dez. 2012. ISSN 1983-4535. Disponível em: https://goo.gl/zo2FAM. Acesso em: 18 fev. 2017.

FREITAS, L. F. de. Grupo Focal: Instrumento de Abordagem Qualitativa Empregado em Pesquisas Secretariais. In: Pesquisa em Secretariado: Reflexões acerca da Construção do Conhecimento. [DURANTE, D. G.; MARTINS, C. B.; CANTAROTTI, A. (Org.)]. Fortaleza: Edições UFC, 2016. p. 213-256.

GALVIS-LISTA, E. A.; GONZÁLEZ-ZABALA, M. P. Herramientas para la gestión de procesos de negocio y su relación con el ciclo de vida de los procesos de negocio: una revisión de literatura. Ciencia e Ingeniería Neogranadina, v. 24, n. 2, p. 37-55, dez. 2014. ISSN 1909-7735. Disponível em: https://goo.gl/BKy19c. Data de acesso: 7 ago. 2017.

GARCIA, R. G.; FARIAS FILHO, M. C.; GARCIA HERREROS, M. M. A. A institucionalização do planejamento na gestão universitária. Revista Gestão Universitária na América Latina, Florianópolis, p. 252-268, set. 2013. ISSN 1983-4535. Disponível em: https://goo.gl/SrxFPw. Acesso em: 04 nov. 2017.

GERHARDT, T. E.; SILVEIRA, D. T (Org). Métodos de pesquisa. Porto Alegre: Editora da UFRGS, 2009.

GISSONI, L. R. de M.; COSTA JÚNIOR, H. L. Implantação de Mapeamento de Processos de Trabalho no Setor de Transporte de uma Instituição Federal de Ensino. In: CONGRESSO NACIONAL DE 
MESTRADOS PROFISSIONAIS DE ADMINISTRAÇÃO PÚBLICA, 1., 2016, Curitiba. Anais eletrônicos. p. 1-12. Disponível em: https://goo.gl/y52bbE. Acesso em: 23 ago. 2017.

GUEDES, V. L. S. A bibliometria e a gestão da informação e do conhecimento científico e tecnológico: uma revisão da literatura. Ponto de Acesso, Salvador, v. 6, n. 2, 2012.

HERNÁNDEZ-NARIÑO, A. et al. Generalización de la gestión por procesos como plataforma de trabajo de apoyo a la mejora de organizaciones de salud. Rev. Gerencia y Políticas de Salud, Bogotá, v. 15, n. 31, p. 66-87, dez. 2016. Disponível em: https://goo.gl/SWK7MJ. Acesso em: 7 ago. 2017.

LEAL, F. G.; DALMAU, M. B. L. Análise das competências secretariais requeridas pela Universidade Federal de Santa Catarina em comparação ao perfil profissiográfico do secretário executivo. Revista de Gestão e Secretariado, v. 5, n. 3, p. 143-174, dez. 2014. ISSN 2178-9010. Disponível em: https:// goo.gl/aiosUH. Acesso em: 11 out. 2015.

LEAL, F. G.; FIATES, G. G. S. Competências dos Secretários-Executivos de uma Universidade Pública Federal: Uma Análise a partir da Perspectiva dos Gestores. Revista de Gestão e Secretariado, v. 4, n. 3, p. 30-57, dez. 2013. ISSN 2178-9010. Disponível em: https://goo.gl/eSo1YB. Acesso em: 5 nov. 2017.

McHUGH, P., PENDLEBlURY, A., \& WHEELER III, W. A.. Reengenharia de processos de negócios (No. HD37. R44 1996). Limusa, 1995.

MÜCKENBERGER, E. et al. Gestão de processos aplicada à realização de convênios internacionais bilaterais em uma instituição de ensino superior pública brasileira. Produção, São Paulo, v. 23, n. 3, p. 637-651, set. 2013. Disponível em: https://goo.gl/phjav1. Acesso em: 4 nov. 2017. Epub Oct 26, 2012. http://dx.doi.org/10.1590/S0103-65132012005000076.

NONATO JÚNIOR, R. Epistemologia e teoria do conhecimento em secretariado executivo: a fundação das ciências da assessoria. Fortaleza: Expressão Gráfica, 2009.

OLIVEIRA, J. M. de; GROHMANN, M. Z.; MARQUETTO, M. F. Análise dos processos de aposentadoria e pensão civil de uma Instituição Federal de Ensino. Revista Gestão \& Conexões. Vitória (ES), v. 5, n. 1 jan./jun. 2016. Disponível em: https://goo.gl/Wtj1Vi. Acesso em: 23 ago. 2017. doi: http://10.13071/regec.2317-5087.2016.5.1.11418.141-169

PAES, R. V. O.; ANTUNES, C. S. de S.; SANTIAGO, C. da S.; ZWIERZIKOWSKI, M. R. Novas Formas de Atuação do Profissional de Secretariado Executivo. Revista de Gestão e Secretariado, v. 6, n. 1, p. 99-125, abr. 2015. ISSN 2178-9010. Disponível em: https://goo.gl/n2xWG3. Acesso em: 25 jul. 2015.

PRADELLA, S.; FURTADO, J. C.; KIPPER, L. M. Gestão de processos - da teoria à prática: aplicando a metodologia de simulação para a otimização do redesenho de processos. São Paulo: Atlas, 2012.

ROESCH, S. M. A. Projetos de estágio e de pesquisa em administração: guia para estágios, trabalhos de conclusão, dissertações e estudos de caso. 2.Ed. São Paulo: Atlas, 1999. 
RODRIGUES, L. M. A. et al. A atuação do profissional de secretariado executivo na gestão de processos. Diálogos Interdisciplinares, [Mogi das Cruzes], v. 5, n. 1, p. 65-80, mai. 2016. ISSN 2317-3793. Disponível em: https://goo.gl/J1n7oL. Acesso em: 10 fev. 2017.

SANTOS, R. E. dos. Mapeamento de processos e complexidade de um departamento de patrimônio de uma IFES. 2017. 148 p. Dissertação (Mestrado em Gestão de Organizações e Sistemas Públicos) - Universidade Federal de São Carlos, São Carlos, SP, 2017.

SGANDERLA, K. Um BPMN para cada propósito de modelagem de processos. 2012. Disponível em: <http://blog.iprocess.com.br/2012/04/>. Acesso em: 5 nov. 2017.

SOFTWARE PÚBLICO BRASILEIRO. TRF4 - SEI - Sistema Eletrônico de Informações - Sobre o SEI. 2015. Disponível em: https://softwarepublico.gov.br/social/sei/sobre-o-sei. Acesso em: 1 mar. 2019.

SORDI, J. O. de. Gestão por processos: uma abordagem da moderna administração. 4. ed. São Paulo: Saraiva, 2014.

THIRY-CHERQUES, H. R. Saturação em pesquisa qualitativa: estimativa empírica de dimensionamento. Revista PMKT, v. 3, n. 2, p. 20-27, 2009. Disponível em: https://goo.gl/9m3bzu. Acesso em: 4 nov. 2017.

UNIVERSIDADE FEDERAL DO PARÁ. Pró-Reitoria de Planejamento e Desenvolvimento Institucional. Anuário Estatístico 2017: Ano Base 2016. Belém, 2017. Disponível em: https://goo. gl/Cm2fH3. Acesso em: 29 dez. 2017.

YIN, R. K. Estudo de caso: planejamento e métodos. 5. Ed. Porto Alegre: Bookman, 2015. 